\title{
Correction to: Evaluation of host plant suitability and efficacy of chemical and biological insecticides and insect nets for controlling Liothrips wasabiae (Thysanoptera:Phlaeothripidae)
}

\author{
Kentaro Matsuda ${ }^{1} \cdot$ Daisuke Sasaki $^{1,4} \cdot$ Hajime Haga $^{1} \cdot$ Takuya Nishijima $^{2,5} \cdot$ Yuka Hagiwara $^{3,6} \cdot$ Atsushi Kasai $^{3}$
}

Published online: 26 May 2020

(C) The Japanese Society of Applied Entomology and Zoology 2020

\section{Correction to: Applied Entomology and Zoology https://doi.org/10.1007/s13355-020-00683-w}

In the original publication of the article, the following sentence "To prevent $L$. wasabiae invasion of wasabi nurseries, we recommend insect nets of $d$ males, respectively. Thus their colour." Was published incorrectly under the discussion section. The correct sentence should read as "To prevent L. wasabiae invasion of wasabi nurseries, we recommend insect nets of $\leq 0.3-\mathrm{mm}$ mesh, regardless of their color." The original version was updated.

In addition, the present address of second author "Daisuke Sasaki" is "Present Address: Kamikawa Agricultural Experiment Station, Agricultural Research Department, Hokkaido
Research Organization, Minami-issen, Pippu, Kamikawa, Hokkaido 078-0397, Japan”.

Publisher's Note Springer Nature remains neutral with regard to jurisdictional claims in published maps and institutional affiliations.
The original article can be found online at https://doi.org/10.1007/ s13355-020-00683-w.

Kentaro Matsuda

kentaro1_matsuda@pref.shizuoka.lg.jp

1 Shizuoka Plant Protection Office, Tomigaoka, Iwata, Shizuoka 438-0803, Japan

2 Wasabi Productional Technology Division, Izu Agricultural Research Center, Shizuoka Prefectural Research Institute of Agriculture and Forestry, Yugashima, Izu, Shizuoka 413-3206, Japan

3 Department of Agriculture, Graduate School of Integrated Science and Technology, Shizuoka University, Ohya, Suruga, Shizuoka, Shizuoka 422-8529, Japan

4 Present Address: Agricultural Research Department, Kamikawa Agricultural Experiment Station, Hokkaido Research Organization, Minami-issen, Pippu, Kamikawa, Hokkaido 078-0397, Japan

5 Present Address: Izunokuni, Japan

6 Present Address: Agriculture and Forestry Office for Chuen Region of Shizuoka Prefecture, Mitsuke, Iwata, Shizuoka 438-0086, Japan 